\section{Lever holding and avoidance in the rat, with constant current and constant voltage UCS*}

\author{
PETER GRIGG + \\ Syracuse University, Syracuse, N.Y. 13210
}

Rats were given lever-press avoidance trials with constant current (CC) or constant voltage (CV) UCS. A wide range of intensities of $\mathrm{CC}$ and $\mathrm{CV}$ shock were used to train groups of $10 \mathrm{Ss}$ each. A lever-holding response appeared as an increasing function of intensity of $\mathrm{CC}$ but not of $\mathrm{CV}$ shock.

It is known that when Ss are trained to press a lever to escape or avoid a UCS, they learn to hold the lever down (Keehn, 1967; Migler, 1963). Furthermore, it has been suggested that this lever-holding behavior interferes with the appearance of a lever-press response (Feldman \& Bremner, 1963).

In the present study, lever holding and avoidance responding were evaluated using constant current (CC) and constant voltage (CV) shock sources. A CV source is characterized by a low output voltage and has a small resistance in series with the $\mathrm{S}$. A $\mathrm{CC}$ source is characterized by a high output voltage and has a large resistance in series with the animal. Campbell \& Teghtsoonian (1958) demonstrated that Ss shocked with a CV UCS were more active than those shocked with a CC UCS at an equivalent intensity. In the present experiment, during escape trials, when the CS and the UCS are presented together, responses elicited by the UCS would be classically conditioned to the CS. Therefore, Ss trained to escape/avoid a CV shock should tend to be more active during the CS presentations, and it was hypothesized that such activity would diminish lever holding and freezing during the $\mathrm{CS}$, and thus enhance avoidance (Wahlsten, Cole, Sharp, \& Fantino, 1968).

Groups of Ss were given avoidance training with $\mathrm{CC}$ or $\mathrm{CV}$ shock. Since a means for equating subjective intensity of the two types of UCS was not available, or (see discussion) perhaps inappropriate, groups of Ss were assigned to a wide range of intensities of $\mathrm{CC}$ and $\mathrm{CV}$ shocks. It was planned to make quantitative comparisons between the best-performing groups of each type of UCS.

\section{METHODS}

Ss were 94 male hooded rats from the animal colony at Syracuse University. Ss

*Supported in part by Research Grants M-2064, from the National Institute of Mental Health, and GP-1137, from the National Science Foundation.

+Now at the Department of Physiology, The Johns Hopkins University, School of Medicine, Baltimore, Md. 21205. were 60.90 days of age, and weighed 290-350 g. The apparatus consisted of two Grason-Stadler operant conditioning units, each with an E3125A single-lever rat box. The lever was electrically isolated from the cage. The CS (white noise) preceded the UCS presentation by 5.3 sec. A lever-press response during the $C S$ terminated the $C S$, avoided the UCS, and was termed an avoidance response. A lever-press response during the CS-UCS presentation terminated the CS and UCS, and was termed an escape response. When the lever was held down before CS onset, and during the entire duration of the CS, a lever-hold response was counted and the CS-UCS was neither avoided nor escaped. In the absence of an escape or avoidance response, CS and UCS were terminated after $60 \mathrm{sec}$. Intertrial interval was variable, with a mean duration of $40 \mathrm{sec}$. The CC shocker was a Grason-Stadler E1064GS shock generator. The CV shock was generated with a Powerstat variable transformer, delivered to the grid floor through a Triad N-51X isolation transformer and the scrambling unit of the E1064GS. A $1 \mathrm{~K}$ resistor was placed in series with the animal. UCS Block 6) for each group. intensities were: $\mathrm{CC}-0.4,0.5,0.6,0.8$, and $1.0 \mathrm{~mA} ; \mathrm{CV}-25,30,35,40$, and $45 \mathrm{~V}$.

Fifty trials were given on Day 1 . No attempt was made by the investigator to shape the animals' responses. Two hundred and fifty trials were administered on Day 2, and the experiment was terminated. Ten $S$ s were assigned to each group. However, the resistance of Ss shocked with a CV shock dropped rapidly from $70 \mathrm{~K}$ shock, no further Ss were assigned to that group. Those data, while included in figures, were excluded from the statistical analyses.

\section{RESULTS}

For each block of 50 trials, the number of avoidance, escape, and lever-hold responses was determined.

\section{Lever-Holding Response}

Of the measures taken, an effect of type of UCS was seen only in lever-holding behavior. The percentage of lever-hold responses observed in each group during the last 50 trials of Day 2 are shown in Fig. 1. Lever-holding behavior was an increasing function of intensity of $\mathrm{CC}$ shock, a relationship not found with $\mathrm{CV}$ shock. Pairwise comparisons of the nine group means were made with the Tukey (b) test. Group $1.0 \mathrm{~mA}$ was greater than all $\mathrm{CV}$ groups, and all $\mathrm{CC}$ groups except $0.8 \mathrm{~mA}$, at the 0.01 level. All other means were statistically homogeneous.

\section{Avoidance Response}

There was no significant effect of type or intensity of UCS on avoidance responding. The grand mean percentage of avoidance responses made by each group in 300 trials is shown in Fig. 2, "normal." All groups except $25 \mathrm{~V}$ made avoidance responses; comparisons of the nine group means were made with the Tukey (b) test,

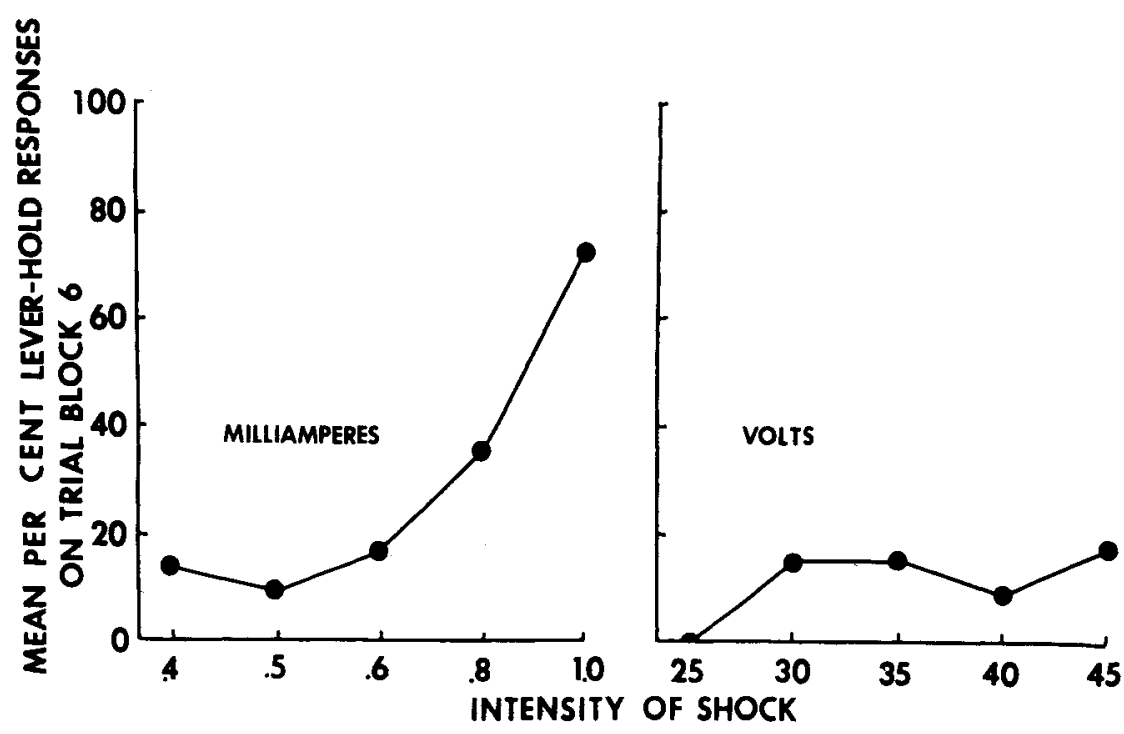

Fig. 1. Mean percentage of lever-hold responses observed in the last 50 trials (Trial 


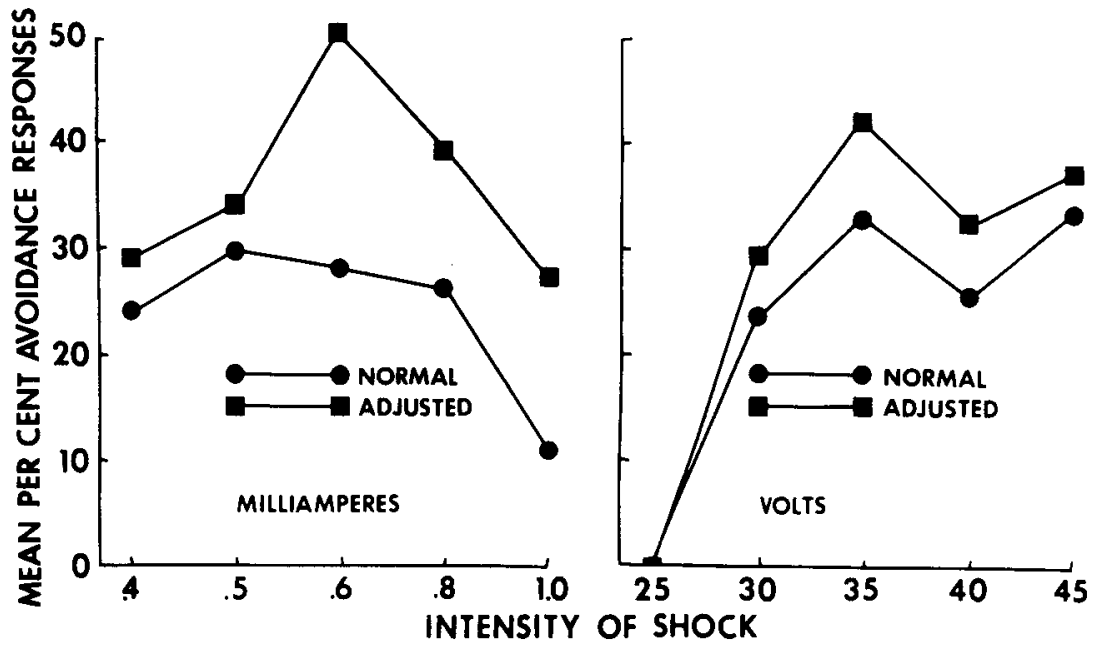

but no pairwise comparison was significant at the 0.05 level.

Since a lever-hold response precluded the occurrence of an avoidance response, the percentage of avoidance responses was adjusted to include only those trials on which the $S$ did not hold the lever. These data are shown in Fig. 2, as "adjusted." Pairwise comparisons of means were still not significant when tested with the Tukey (b) test. The Pearson product moment correlation was computed between the number of lever-hold responses and the number of avoidance responses for each $S$. The result, $I_{x y}=-0.49$, was highly significant $\mathrm{t}(88)=-5.29, \quad \mathrm{p}<0.001$, confirming the fact that the two responses are mutually exclusive. Furthermore, in groups where lever-holding was high, Ss are unlikely to perform well since in these groups the highly developed tendency to hover near the lever may impair avoiding even when the lever was not held (Bolles \& McGillis, 1968): Accordingly, in Groups 0.8 and $1.0 \mathrm{~mA}$, Pearson product moment correlations were -0.74 and -0.89 , significant at the 0.05 and 0.01 levels, respectively.

\section{Other Measures}

In an attempt to obtain behavioral indicies of the subjective intensity of UCS, on Day 1 the speeds of the escape responses were measured and the number of shock-elicited feces were counted. Differences between groups were not significant.

\section{DISCUSSION}

In interpreting the results of this experiment, it must be stressed that the experimental design may confound the two factors, type and intensity of UCS. It might be argued that Ss trained at $1.0 \mathrm{~mA}$ held the lever more than those trained at $45 \mathrm{~V}$ because the former UCS had a greater subjective intensity than the latter. Several factors, however, diminish this possibility: (1) Levels of $\mathrm{CV}$ shock greater than $45 \mathrm{~V}$ were consistently found to be injurious to Ss, and it seemed that $45 \mathrm{~V}$ was the highest intensity of CV UCS usable in this situation, and (2) behavioral indicies of UCS intensity did not indicate any marked difference in intensities of $\mathrm{CC}$ and $\mathrm{CV}$ shocks.

A quantitative method of evaluating the subjective intensity of two shocks, such as that employed by Campbell \& Teghtsoonian (1958) was not available, and may not have been appropriate. Those investigators considered two shocks to be of equivalent intensity when they were an equal number of decibels above threshold. However, the resistance of Ss shocked with a $\mathrm{CV}$ shock dropped rapidly from $70 \mathrm{~K}$ to $2.5 \mathrm{~K}$ with exposure to UCS; this was not true for Ss exposed to CC shock. Since an S's threshold may be a function of its resistance, it is likely that the threshold of $\mathrm{Ss}$ in CV groups changed with exposure to shock. In this experiment, by comparing the best response level obtained with each type of UCS, the effect of intensity would presumably be optimized with each. The fact that there is no evidence with $\mathrm{CV}$ of any relationship of lever holding and UCS intensity, while a prominent relationship exists with $\mathrm{CC}$, strongly suggests that the results demonstrate a true effect of type of UCS.

The CC and CV shocks employed were shown to have a differential effect on lever-holding behavior in the lever-press avoidance situation. Despite the marked differences in lever holding caused by the two types of shock, and the demonstrated incompatibility of avoidance and lever holding, avoidance responding was equivalent with both $\mathrm{CC}$ and $\mathrm{CV}$ shock. Other investigators have shown that avoidance behavior can be improver by several contingencies that diminish lever holding. For example, punishing lever-holding responses (Feldman \& Bremner, 1963; Jones \& Swanson, 1966),
Fig. 2. Grand mean percentage of avoidance responses for each group. "Normal": Number of avoidance responses expressed as a percentage of all 300 trials. "Adjusted": Number of avoidance responses expressed as a percentage of those trials on which the $S$ did not hold the lever.

removing the lever during the intertrial interval (Cole \& Fantino, 1966), or removing the $S$ from the lever (Fantino, Sharo, \& Cole, 1966), all have been shown to improve avoidance responding. On the other hand, Wahlsten et al (1968) found that the handling of Ss improved avoidance regardless of whether the lever was held or not. They concluded that it was not the lever-hold response itself that was responsible for the absence of an avoidance response.

In the present experiment, the $\mathrm{CV}$ groups that did not hold the lever did not avoid better than the $\mathrm{CC}$ groups that did hold the lever. Thus, the results may be interpreted to support the finding of Wahlsten et al (1968).

The results did not support the hypothesis that CS-evoked movements with $\mathrm{CV}$ shock would lead to improved avoidance responding. CS-evoked movements may have been responsible for the decreased lever holding in $\mathrm{CV}$ groups, but if so, they were not sufficient to alter avoidance in any way.

\section{REFERENCES}

BOLLES, R. C., \& MCGILLIS, D. B. The non-operant nature of the bar-press escape response. Psychonomic Science, 1968, 11, 261-262.

CAMPBELL, B. A., \& TEGHTSOONIAN, R. Electrical and behavioral effects of different types of shock stimuli on the rat. Joumal of Comparative \& Physiological Psychology, $1958,51,185-192$.

COLE, M., \& FANTINO, E. Temporal variables and trial discreteness in lever-press avoidance. Psychonomic Science, 1966, 6, 217-218.

FANTINO, E., SHARP, D., \& COLE, M. Factors facilitating lever-press avoidance. Journal of Comparative \& Physiological Psychology, $1966,62,214-217$.

FELDMAN, R. S., \& BREMNER, F. J. A method for rapid conditioning of stable avoidance bar pressing behavior. Journal of the Experimental Analysis of Behavior, 1963, 6, 393-394.

JONES, E. C., \& SWANSON, A. M. Discriminated lever-press avoidance. Psychonomic Science, 1966, 6, 351-352.

KEEHN, J. D. Is bar-holding with negative reinforcement preparatory or perserverative? Journal of the Experimental Analysis of Behavior, 1967, 10, 461-465.

MIGLER, B. Bar holding during escape conditioning. Journal of the Experimental Analysis of Behavior, 1963, 6, 65-72.

WAHLSTEN, D., COLE, M., SHARP, D., \& FANTINO, E. Facilitation of bar-press avoidance by handling during the intertrial interval. Journal of Comparative \& Physiological Psychology, 1968, 65, 170-175. 